\title{
PKM Kelompok Pendamping Nifas (KP Nifas) di Posyandu Desa Ledug Kecamatan Kembaran Kabupaten Banyumas Jawa Tengah
}

\author{
PKM Nifas Escort Group (KP Nifas) in Posyandu Ledug Village Twin District Banyumas \\ Central Java
}

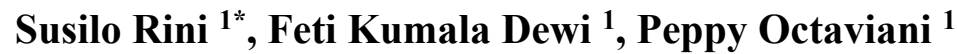 \\ ${ }^{1}$ Prodi Kebidanan D3 Universitas Harapan Bangsa Purwokerto \\ *susilorini@uhb.ac.id
}

\begin{abstract}
ABSTRAK
Desa Ledug Kembaran Banyumas yang mempunyai permasalahan tingginya angka morbiditas dan mortalitas ibu dan bayi pada masa nifas serta rendahnya cakupan ASI eksklusif. Tahun 2017 cakupan ASI eksklusif hanya 68\%, dikarenakan ASI tidak keluar, putting lecet dan nyeri jahitan, 3\% ibu mengalami infeksi pada luka perineum, serta rendahnya cakupan KB, 276 PUS dari 854 PUS belum menjadi akseptor KB. Periode Januari- April 2018 terdapat 3 Angka Kematian Bayi. Permasalahan tersebut dapat dikarenakan belum adanya kelompok pendukung ibu nifas, kurangnya sarana informasi perawatan bayi baru lahir, perawatan ibu nifas, dan Pemilihan Metode KB. Pada Maret 2018 ada 28 kader posyandu belum mengetahui bentuk dukungan bagi ibu nifas. Kegiatan ini bertujuan untuk membentuk kelompok pendamping ibu nifas (KP-Nifas) di Desa Ledug yang diharapkan mampu mengoptimalkan peran kader dalam memberdayakan ibu nifas dan keluarganya, agar ibu dan bayinya melewati masa nifas dengan sehat dan menyenangkan. Tahapan kegiatan yang dilaksanakan dalam pembentukan KP Nifas tersebut antara lain: 1) Perijinan, 2) Koordinasi, 3) Pembuatan Materi 4) pelatihan Kader, 5) Pembentukan KP Nifas, dan 6) Pelaksanaan posyandu dengan KP Nifas. Target Luaran dhasil kegiatan ini adalah publikasi pada jurnal ilmiah, terbentukanya KP Nifas, tersedianya buku saku KP nifas, leaflet perawatan ibu nifas, perawatan bayi baru lahir dan manajemen ASI eksklusif beserta videonya yang berfungsi membantu meningkatkan pengetahuan dan kesadaran masyarakat tentang pentingnya perawatan dan dukungan bagi ibu nifas dan menyusui eksklusif. Kehadiran Kelompok Pendamping ibu nifas ini dapat memudahkan akses informasi di posyandu yang dilaksanakan setiap bulan oleh masyarakat untuk berkonsultasi berbagi pengalaman serta informasi antara ibu nifas, kader dan tenaga kesehatan sehingga dapat meminimalisasi masalah-masalah selama masa nifas serta meningkatkan cakupan ASI ekslusif.
\end{abstract}

Kata kunci — Kelompok Pendamping Ibu Nifas, Kader, Posyandu

\begin{abstract}
Ledug Kembaran Banyumas village has problems with high morbidity and mortality of mothers and infants at the time of nifas and low exclusive breast milk coverage. In 2017 exclusive breast milk coverage was only 68\%, because breast milk did not come out, putting blisters and stitch pain, 3\% of mothers had infections in perineum wounds, as well as low kb coverage, 276 PUS from 854 PUS has not been a KB acceptor. From January to April 2018 there were 3 Infant Mortality Rates. The problem can be due to the absence of support groups of nifas mothers, lack of information facilities for newborn care, maternal care, and selection of birth control methods. In March 2018 there were 28 posyandu cadres who did not know the form of support for nifas mothers. This activity aims to form a group of nifas mothers (KP-Nifas) in Ledug Village who are expected to optimize the role of cadres in empowering nifas mothers and their families, so that mothers and babies pass through the nifas period in a healthy and enjoyable manner. Stages of activities carried out in the formation of KP Nifas include: 1) Licensing, 2) Coordination, 3) Making Of Materials 4) training cadres, 5) Formation of KP Nifas, and 6) Implementation of posyandu with $K P$ Nifas. External targets of this activity are publications in scientific journals, the formation of KP Nifas, the availability of KP nifas pocketbooks, nifas maternal care leaflets, newborn care and breast milk managementexclusively and its videos that serve to help increase public knowledge and awareness about the importance of care and support for mothers nifas and exclusive breastfeeding. The presence of this nifas mother Companion Group can facilitate access to information in posyandu held every month by the community to consult sharing experiences and information between nifas mothers, cadres and health workers so as to minimize problems during the nifas period and increase exclusive breast milk coverage.
\end{abstract}

Keywords - Companion Group of Mrs. Nifas, Kader, Posyandu 


\section{Pendahuluan}

Diperkirakan bahwa $60 \%$ kematian ibu terjadi setelah persalinan dan 50\% kematian masa nifas terjadi dalam 24 jam. Data Dinas Kesehatan Jawa Tengah, AKI di Jawa Tengah meningkat karena ada kecenderungan kematian ibu melahirkan meningkat dalam lima tahun terakhir. Kejadian AKI di Banyumas paling banyak adalah pada waktu nifas sebesar 58\% kasus yang terjadi pada 3 hari postpartum. Kabupaten Banyumas merupakan zona merah dalam target kunjungan nifas (KF) yang baru mencapai 82,1\% (Achyar, K. and Rofiqoh, I., 2016) [1]. Asuhan masa nifas sangat diperlukan, karena merupakan periode kritis baik bagi ibu maupun bayinya.

Menurut wawancara dengan Bidan desa dan ibu penggerak PKK desa Tambaksari, belum terdapat kelompok khusus yang memberikan perhatian kepada ibu nifas. Informasi yang didapatkan sangat terbatas, dari orang tua yang terkadang malah tidak benar, anggapan setelah proses persalinan maka ibu tidak lagi perlu mendapat perhatian dan kewaspadaan karena dianggap bukan lagi merupakan masa kritis. Bidan desa membutuhkan dukungan masyarakat untuk membantu memberikan edukasi dan mendukung ibu melewati masa nifas. Hal ini dapat berdampak pula pada penurunan kematian bayi karena pengetahuan dan kondisi ibu nifas yang baik (sehat jasmani dan rohani) selama melakukan perawatan pada bayinya. Sedangkan kader posyandu selama ini hanya dapat memberitahu yang berkaitan dengan pertumbuhan dan perkembangan bayi belum berfokus pada perawatan ibu masa nifas, perawatan bayi baru lahir maupun Pemberian ASI eksklusif.

Permasalahan dan tantangan yang dihadapi mitra adalah adanya masalah ibu nifas Tiga Ibu nifas $(2,6 \%)$ mengalami post partum blues ringan, dan 7,9\% mengalami infeksi pada luka perineum, juga terdapat 3 kematian bayi baru lahir serta rendahnya cakupan ASI. Permasalahan tersebut adalah karena belum adanya kelompok pendukung Ibu Nifas, kurangnya sarana informasi tentang pentingnya ASI Eksklusif bagi bayi, perawatan bayi baru lahir, dan perawatan ibu nifas. Pada Maret 2016 ada 15 kader posyandu belum mengetahui menyusui ASI eksklusif dengan benar dan bentuk dukungan bagi ibu nifas.

Masalah ibu nifas di Desa Tambaksari menjadi prioritas untuk ditindaklanjuti. Hal ini berdasarkan pertemuan dengan Kepala desa, Ibu penggerak PKK, kader posyandu balita dan juga Bidan desa. Menurut Ibu Kepala Desa kesehatan ibu hamil, bayi dan balita serta lansia sudah banyak menjadi sorotan dari berbagai pihak. Berbeda dengan Ibu nifas yang tidak tampak menjadi masalah, ternyata cakupan ibu nifas yang menyusui secara eksklusif masih rendah. Kematian bayi baru lahir dengan berat badan rendah juga perlu dicegah dengan pemberian informasi kepada ibu/ keluarga tentang perawatan dan tanda bahaya bayi baru lahir.

Pendekatan yang digunakan dalam rangka penyelesaian masalah yakni dengan pemberdayaan masyarakat melalui 2 kelompok pendukung ibu nifas di 2 posyandu. Terbentuknya KP-Nifas diharapkan mampu memberdayakan ibu nifas dan keluarganya agar ibu dan bayinya melewati masa nifas dengan sehat dan menyenangkan. Wujud kegiatan KPnifas antara lain Senam Nifas, KIE pijat oksitosin bagi suami kepada ibu nifas, KIE perawatan payudara dan cara menyusui yang benar, pemenuhan gizi Ibu menyusui, cara merawat luka perineum, Perawatan bayi baru lahir dan kemudahan akses informasi di dua titik posyandu yang terjangkau jaraknya untuk berkonsultasi dan berbagi antara ibu nifas, sehingga dapat meminimalkan masalah-masalah selama masa nifas.

Adapun solusi yang ditawarkan dalam penerapan Pengabdian Masyarakat ini adalah :

a. Membentuk Kelompok pendukung Ibu Nifas

b. Meningkatkan Komunikasi, Informasi dan edukasi (KIE) bagi ibu nifas, keluarga dan kader kesehatan dengan pembuatan media komunikasi seperti Buku saku dan leaflet tentang perawatan ibu nifas, perawatan bayi baru lahir dan Ragam alat kontrasepsi.

c. Meningkatkan kesadaran masyarakat melalui KIE bahwa masa nifas masuk dalam masa kritis ibu yang harus mendapat perhatian dan dukungan

d. Memberikan penyuluhan atau pelatihan bentuk dukungan bagi ibu nifas. 


\section{Target dan Luaran}

Jenis luaran yang akan dihasilkan dari kegiatan Pengabdian Masyarakat ini adalah :

a. Terbentuknya kelompok pendukung Ibu Nifas.

b. Meningkatnya komunikasi, informasi dan edukasi tentang perawatan ibu nifas, perawatan bayi baru lahir dan tata laksana menyusui eksklusif : pembuatan Buku saku dan leaflet tentang Perawatan Ibu nifas: senam nifas- pijat oksitosin-perawatan luka perineum-gizi ibu nifas-Tanda Bahaya ibu nifas, Perawatan Bayi Baru lahir: tanda bahaya bayi baru lahir-perawatan tali pusatmemandikan bayi Tatalaksana Menyusui Eksklusif: Cara Menyusui yang benarPerawatan Payudara-Masalah Menyusui dan penanganannya.

c. Adanya kesadaran masyarakat tentang pentingnya dukungan bagi Ibu Nifas.

d. Peningkatan pengetahuan kader, ibu dan keluarga melalui penyuluhan/ pelatihan tentang Perawatan Ibu nifas, Perawatan bayi baru lahir, Tata laksana menyusui eksklusif bagi Ibu nifas menyusui.

e. Publikasi Ilmiah di Jurnal Nasional.

\section{Metodologi}

Posyandu merupakan pos pelayanan terpadu yang keberadaannya dekat dengan masyarakat dan program yang sudah ada adalah posyandu balita dan posyandu Lansia. Pengertian Posyandu sendiri adalah kegiatan kesehatan dasar yang diselenggarakan dari, oleh dan untuk masyarakat yang dibimbing oleh petugas kesehatan terkait. Program yang diusulkan dalam IbM ini adalah meningkatkan fungsi dan program dinas kesehatan.

Metode pelaksanaan dalam kegiatan ini adalah dengan menambah dan meningkatkan fungsi posyandu dengan membentuk Kelompok Pendukung Ibu Nifas (KP Nifas) yang berasal dari kader posyandu yang ada di wilayah posyandu RW 4 dan posyandu RW 5 Desa Tambaksari, kemudian dilakukan pelatihan agar anggota kelompok tersebut mampu memberikan konseling, Informasi dan edukasi tentang perawatan ibu nifas, perawatan bayi baru lahir dan manajemen ASI eksklusif kepada masyarakat. Kader kesehatan tersebut berasal dari masyarakat yang bekerja secara sukarela untuk menjadi penyelenggara kegiatan pemberdayaan masyarakat di bidang kesehatan (Tjahyowati, dkk.1997) [11]. Setelah pelatihan KP Nifas implementasi kegiatan posyandu dilakukan sebulan sekali di minggu ke dua setiap bulannya. Kegiatan posyandu tidak lagi hanya 5 meja namun menjadi posyadu model dengan tambahan KP Nifas dengan alur: Meja 1 (pendaftaran), Meja 2 (penimbangan), Meja 3 (pencatatan), Meja 4 (konseling), meja 5 (pelayanan kesehatan) ditambah sebuah ruangan khusus tempat berkumpul ibu nifas/ keluarga untuk melaksanakan pertemuan tentang penyuluhan perawatan ibu nifas, bayi baru lahir dan Manajemen ASI eksklusif. Kegiatan posyandu ini dapat memberikan pengetahuan dan sikap positif para ibu menyusui terhadap pentingnya perawatan dan dukungan bagi ibu nifas dan menyusui eksklusif.

\section{ALUR KEGIATAN KP NIFAS}

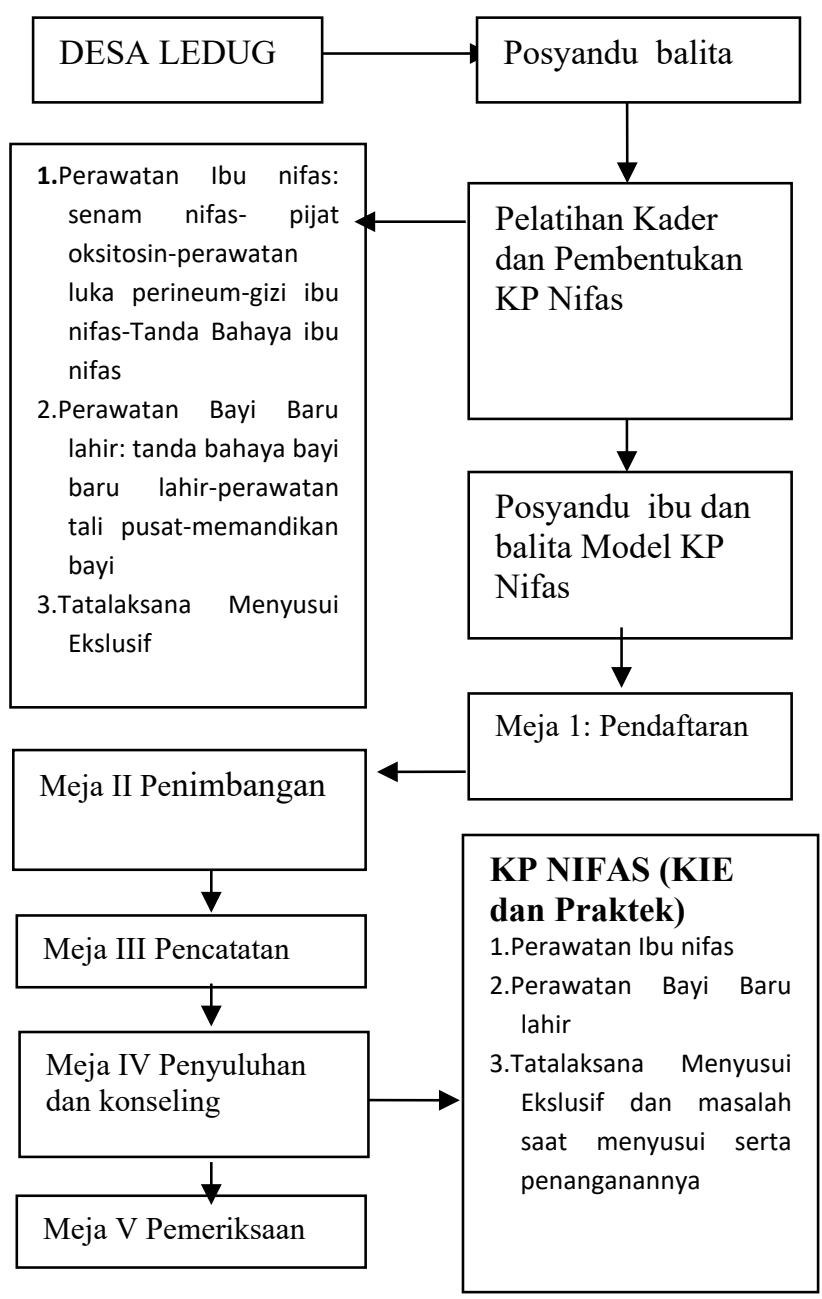

Gambar 1. Alur Kegiatan 


\section{Pembahasan}

Pelaksanaan IbM telah dilakukan melalui tahapan sebagai berikut:

\subsection{Persiapan}

Sebelum pembentukan Kelompok Pendukung Ibu Nifas (KP Nifas), kami mengurus perijinan ke kesbangpolinmas dan Bappeda Kabupaten Banyumas kemudian dilanjutkan berkoordinasi dengan Dinas Kesehatan Kabupaten, selanjutnya ke puskesmas, dan Desa Ledug sebagai Lokasi. Perijinan berjalan lancar dan mendapatkan sambutan serta dukungan dari Kepala Desa, bidan desa serta kader dan masyarakat.

\subsection{Pelaksanaan}

Kegiatan pengabdian kepada masyarakat ini melalui pendekatan pemberdayaan masyarakat dengan bantuan kader posyandu yang telah ada, kemudian kami menambahkan kegiatan khususnya berkaitan perawatan dan dukungan bagi ibu nifas dan bayinya serta pemberian ASI eksklusif 6 bulan, berupa kegiatan:

a. Memberikan pemahaman lebih tentang perawatan ibu nifas, perawatan bayi baru lahir, dan pentingnya ASI eksklusif.

b. Memfasilitasi pembentukan kelompok pendukung ibu nifas.

c. KIE tentang Perawatan Ibu nifas: senam nifaspijat oksitosin-perawatan luka perineum-gizi ibu nifas-Tanda Bahaya ibu nifas. Perawatan Bayi Baru lahir: tanda bahaya bayi baru lahirperawatan tali pusat-memandikan bayi. Tatalaksana Menyusui Eksklusif: Cara Menyusui yang benar-Perawatan PayudaraMasalah Menyusui dan penanganannya.

d. Pendampingan implementasi kerja kelompok pendukung nifas,

e. Melakukan evaluasi dan refleksi kembali serta penyempurnaan terhadap program yang telah dibuat dan ditindak lanjuti melalui program selanjutnya.

Pelaksanaan kegiatan secara rinci adalah sebagai berikut:

a. Rapat Koordinasi Pembentukan Posyandu KP Nifas, Setelah pembentukan KP Nifas kami menyiapkan materi yang berupa booklet (buku saku), leaflet dan video tentang KP Nifas.

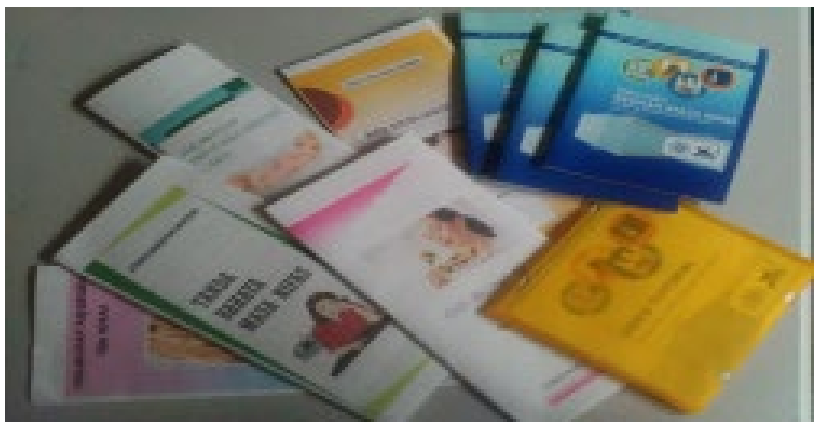

Gambar 2. Produk Luaran

b. Mengadakan pelatihan kader KP Nifas selama 3 hari dengan materi perawatan masa nifas, perawatan bayi baru lahir dan ASI Eksklusif termasuk mengatasi permasalahan/kesulitan yang timbul selama menyusui.

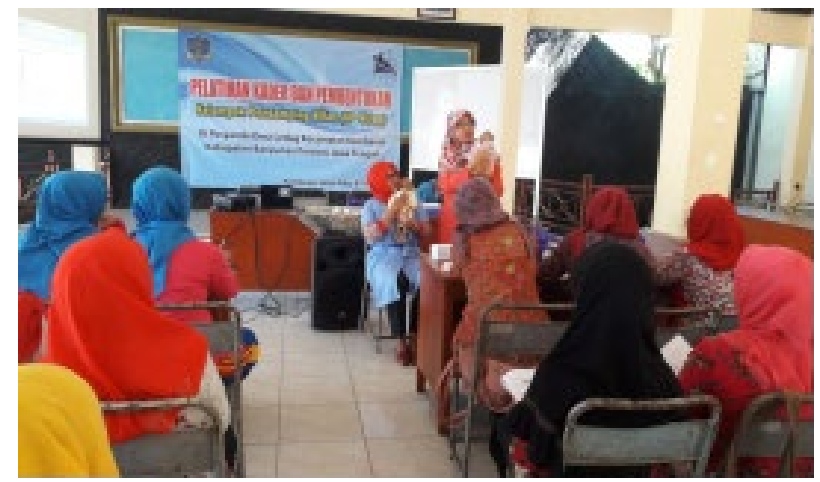

Gambar 3. Pelatihan Kader

c. Pembentukan KP Nifas, Penandatanganan komitmen Bersama untuk melaksanakan kelompok pendamping ibu nifas di Posyandu Desa Ledug

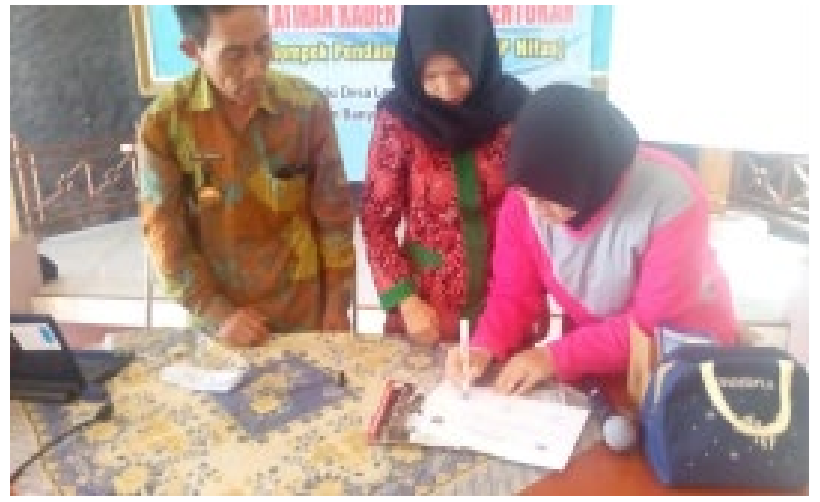

Gambar 4. Pelatihan dan Pembentukan Kader KP Nifas 
d. Jumlah kader di setiap posyandu rata-rata 8 orang yang rata-rata mewakili setiap RT dalam satu RW.

e. Mengadakan pertemuan rutin untuk saling mendukung pada perawatan ibu nifas, bayi baru lahir dan pemberian ASI eksklusif, sehingga meminimalkan masalah selama masa nifas dan menyusui.

f. Mengadakan koordinasi dan kerja sama antar KP Nifas.

g. Mensosialisasikan dukungan bagi ibu nifas dan menyusui eksklusif kepada masyarakat luas.

h. Melibatkan laki-laki/suami/tokoh masyarakat /tokoh agama di dalam setiap kegiatan KPNifas. Dengan terbentuknya KP Nifas diharapkan terciptanya dukungan terhadap ibu nifas dan menyusui eksklusif. Wujud dukungan yang diberikan antara lain perhatian, kesempatan, penciptaan suasana yang mendukung kegiatan menyusui, pemenuhan gizi yang optimal bagi ibu menyusui, kemudahan akses berkonsultasi dan berbagi antara ibu nifas dan menyusui, dan kemudahan memperoleh peralatan penunjang ASI perah bagi ibu bekerja.

i. Komunikasi informasi dan edukasi (KIE) kepada masyarakat tentang perawatan ibu nifas, perawatan bayi baru lahir dan manajemen ASI eksklusif.

Untuk melakukan KIE kepada masyarakat, kelompok pendamping Ibu Nifas khususnya kader juga perlu mempunyai pengetahuan yang lebih tentang persoalan Perawatan Ibu nifas, bayi baru lahir dan ASI eksklusif, sehingga materi yang disampaikan adalah Perawatan Ibu nifas: senam nifas- pijat oksitosin-perawatan luka perineum-gizi ibu nifas-Tanda Bahaya ibu nifas, Perawatan Bayi Baru lahir: tanda bahaya bayi baru lahir-perawatan tali pusat-memandikan bayi, serta Tatalaksana Menyusui Eksklusif: Cara Menyusui yang benar-Perawatan PayudaraMasalah Menyusui dan penanganannya.

\subsection{Monitoring}

Pendampingan posyandu dilaksanakan setiap bulan pada minggu ke dua mulai bulan Juli, setelah pelatihan kader dengan melakukan monitoring.

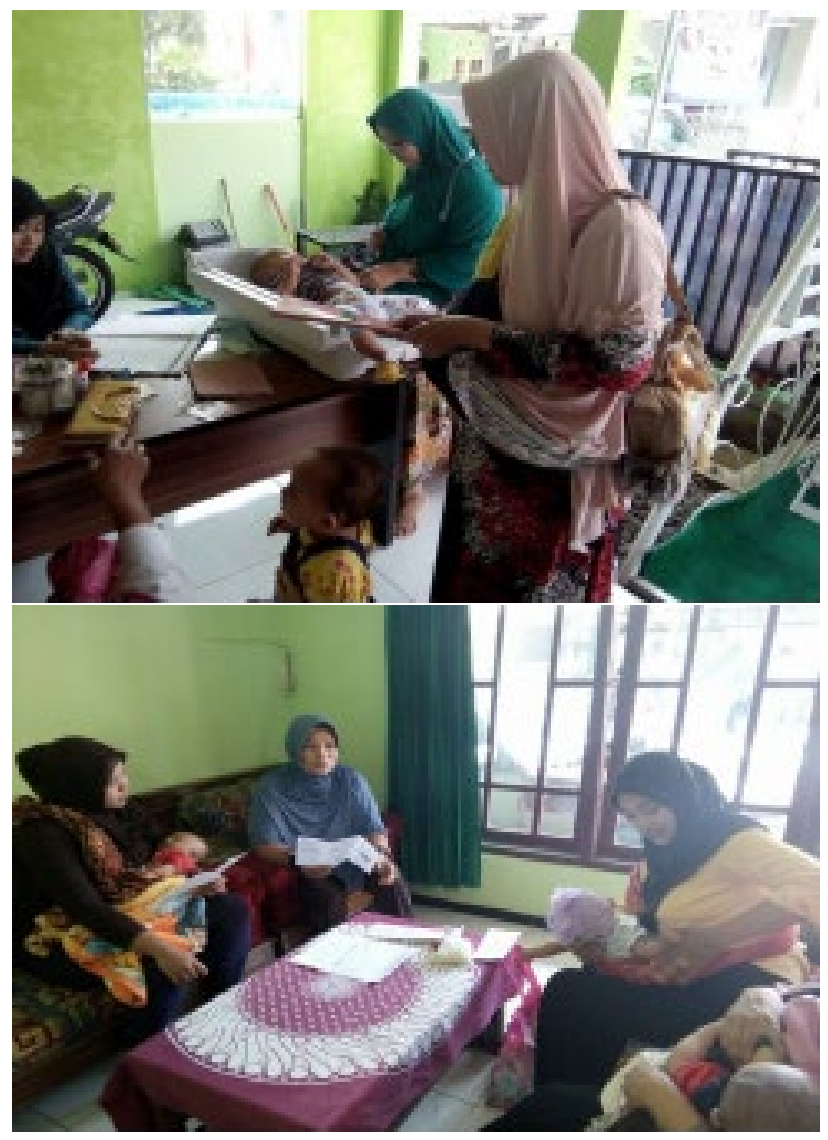

Gambar 5. Kegiatan dan Monitoring Pertemuan KP Nifas

\section{Kesimpulan}

\subsection{Kesimpulan}

Setelah pelaksanaan KP Nifas di Posyandu Desa Ledug, diperoleh kesimpulan bahwa:

a. Kegiatan berjalan dengan lancar dengan terbentuknya kelompok pendukung ibu nifas dengan KP Nifas Desa Ledug yang rutin dilaksanakan pada hari senin dan sabtu minggu ke dua setiap bulannya.

b. Tersusunnya Buku saku, leaflet dan Vidio tutorial KP Nifas yang membantu eksistensi dan keberhasilan kegiatan.

c. Meningkatnya kesadaran masyarakat tentang pentingnya dukungan bagi ibu nifas, yang terlihat dari keaktifan kunjungan KP nifas pada saat posyandu.

d. Meningkatnya komunikasi, informasi dan edukasi masyarakat khususnya kader KP Nifas tentang perawatan ibu nifas, perawatan bayi baru lahir dan tatalaksana menyusui esklusif yang dibuktikan dengan meningkatnya nilai posttest pasca pelatihan 
dan kemampuan mengelola KP NIfas di Posyandu.

e. Tersusunnya Artikel jurnal ilmiah nasionaln dan buku ajar Panduan Asuhan Nifas.

\subsection{Saran}

\subsubsection{Bagi Masyarakat}

Masyarakat hendaknya memanfaatkan fasilitan KP Nifas untuk meningkatkan kesehatan ibu nifas dan bayinya.

\subsubsection{Bagi Pemerintah Desa/ Daerah}

Pemerintah hendaknya mendukung pengembangan program agar dapat diinisiasi ke posyandu lain dan menjaga kontinuitas serta eksistensi kegiatan.

\section{Ucapan Terima Kasih}

Terimakasih kepada DRPM Kemenristekdikti yang telah memberikan dana hibah pengabdian kepada masyarakat sehingga IbM (KP Nifas) di Posyandu Desa Ledug Kecamatan Kembaran Purwokerto dapat terlaksana dan memberikan kontribusi nyata bagi peningkatan kesehatan masyarakat.

\section{Daftar Pustaka}

[1] Ari Sulistyawati. 2009. Buku Ajar Asuhan Kebidanan Nifas. Jakarta:Andi offset

[2] Bahiyatun. 2009. Buku Ajar : Asuhan Kebidanan Nifas Normal. Jakarta

[3] Eny Ratna A, dkk. 2009. Asuhan Kebidanan Nifas, Jogjakarta:Mitra Cendikia Press

[4] Jannah, N. (2011). Asuhan Kebidanan Nifas. Yogyakarta:Ar-Ruzz.

[5] Julianti, S.Kep, dkk .2014. Materi Pelatihan Postnatal Care. Universitas Indonesia.

[6] Kurniawati, T., Chabibah, U. (2014). Pelaksanaan Pendidikan Kesehatan Tentang Ambulasi Dini Ibu Post Partum. Jurnal Kebidanan dan Keperawatan Vol. 10 hal 54-63

[7] Lestari, EP. (2010). Hubungan Rawat Gabung Dengan Mobilisasi Dini Pada Ibu Nifas Hari Pertama di BPS Endang Desa Banaran Kabupaten Kandangan Kabupaten Kediri. Jurnal AKP No 2. Obstetri Fisiologi. Bagian Obstetri Gynekologi FK UGM.

[8] Rini,S dan Dewi, FK. 2016. Panduan Asuhan Nifas dan Evidence Based Practice. Yogyakarta: Deepublish.
[9] Saifuddin AB. 2002. Buku Panduan nasional : pelayanan Kesehatan maternal dan neonatal. Jakarta : Yayasan Bina Pustaka Sarwono Prawiroharjo

[10] Sitti Saleha. 2009. Asuhan Kebidanan pada masa nifas, Jakarta:Salemba medika

[11] Varney, Helen. 2008. Buku ajar Asuhan Kebidanan Vol 2

[12] Suryani, E. (2013). Pengaruh Pijat Oksitosin terhadap Produksi ASI Ibu Postpartum di BPM Wilayah Kabupaten Klaten. Jurnal Terpadu Ilmu Kesehatan Volum 2 No. 2. 